\title{
QUAL O FUTURO DAS ESCOLAS NO CAMPO?*
}

\author{
Célia Regina Vendramini* \\ Universidade Federal de Santa Catarina (UFSC)
}

RESUMO: Tendo como ponto de partida a questão sobre o futuro das escolas rurais ou do campo, o artigo aborda o contexto social, político e econômico que suporta ou não a existência das escolas, bem como uma análise sobre a situação das escolas em diferentes contextos, particularmente no Brasil, em Portugal e nos Estados Unidos. Problematizamos as respostas dadas pelo poder público, acadêmicos e organizações e movimentos sociais sobre o fechamento, a redução do número de alunos e de comunidades rurais com escola, as condições de funcionamento, a distância percorrida pelos alunos, além das implicações das escolas para a vitalidade do campo. Concluímos que o futuro das escolas está diretamente relacionado com o futuro do campo. Palavras-chave: Escola do campo. Escola rural. Brasil. Estados Unidos. Portugal.

\section{WHAT IS THE RURAL SCHOOL'S FUTURE?}

ABSTRACT: Taking the future of rural schools as a starting point, this paper approaches the social, political and economic context that either supports or doesn't support the presence of rural schools. We also offer schools' analysis in different contexts, particularly in Brazil, Portugal and United States. We problematize the public, academic and communal responses on school closure, the student's number and rural communities with schools' reduction, their operating conditions, the distance traveled by the students and the schools' importance to the vitality of the countryside. We conclude that the future of schools is directly related to the future of the countryside. Keywords: Rural education. Brazil. United States. Portugal.

http://dx.doi.org/10.1590/0102-4698126111

"Este artigo foi elaborado durante estágio pós-doutoral na Universidade de Cornell, nos Estados Unidos (2012 a 2013) e contou com financiamento da CAPES (Bolsa Estágio Sênior).

"* Doutora em Educação pela Universidade Federal de São Carlos (UFSCAR). Professora e pesquisadora no Núcleo de Estudos sobre as Transformações no Mundo do Trabalho da Universidade Federal de Santa Catarina. E-mail: celia.vendramini@ufsc.br 


\section{INTRODUÇ̃̃̃O}

Há uma realidade comum nas escolas rurais, em diferentes contextos, no que se refere ao seu fechamento, à diminuição do número de alunos e de comunidades rurais com escola, à distância percorrida pelos alunos, além das implicações das escolas para a vitalidade do campo.

Problematizamos neste artigo o contexto social, político e econômico que suporta ou não a existência das escolas. Consideramos necessário compreender a realidade do campo, suas mudanças, bem como as formas de resistência e luta que lá emergem, para analisar a especificidade das escolas de forma mais ampla e crítica.

Objetivamos analisar a situação das escolas rurais ou do campo em diferentes contextos, bem como as soluções propostas por acadêmicos, pelas políticas governamentais e pelos movimentos sociais para os problemas da escola no que diz respeito às suas condições de funcionamento, à redução do número de alunos e até mesmo o seu fechamento.

Tomamos como referência nossos estudos desenvolvidos no Brasil, particularmente acerca da realidade da educação nos acampamentos e nos assentamentos do Movimento dos Trabalhadores Rurais Sem Terra ${ }^{1}$, bem como nossas pesquisas desenvolvidas nos Estados Unidos ${ }^{2}$ e em Portugal ${ }^{3}$. Com base nessas diferentes realidades, mas que mantêm uma base em comum, pretendemos refletir sobre os limites das soluções propostas para as escolas no espaço rural.

\section{A ATUALIDADE DO CAMPO}

Não é novidade afirmar que o campo tem passado por profundas mudanças. Cabe compreender a natureza de tais mudanças, suas implicações para a população e as formas de resistência que têm sido criadas em âmbito individual e coletivo.

A partir dos anos de 1970, observamos novos elementos na conjuntura do capitalismo global, com novas modalidades de acumulação, que mudaram a questão agrária centrada em parcerias nacionais de desenvolvimento do capitalismo no campo e sua contribuição para a industrialização. Bernstein (2013, p. 3-4) aponta os principais elementos decorrentes desse quadro: liberalização do comércio; financeirização; remoção de subsídios e outras formas de apoio aos pequenos agricultores no Sul e medidas austeras requeridas pelo neoliberalismo; aumento da concentração das corporações globais, marcado pelas fusões e as aquisições, e poder econômico de algumas corporações comandando quotas de mercado maiores; novas tecnologias 
organizacionais ao longo das cadeias de mercadorias; patenteamento dos direitos de propriedade intelectual (biopirataria); novas fronteiras técnicas de engenharia de plantas e material geneticamente modificado; perda da biodiversidade; novas fronteiras de lucro da produção de agrocombustíveis; consequências para a saúde; custos ambientais; e, por fim, as questões da sustentabilidade do atual sistema mundial de alimentos, que está acelerando contradições biofísicas.

A agricultura tornou-se central na financeirização da economia em âmbito mundial. Há uma motivação do agronegócio e do setor financeiro para fusões, compras e arrendamentos de terras, dadas a lucrativa produção e a especulação no valor dos recursos naturais dos produtos e da terra. O Estado tem papel vital em tornar a terra disponível para corporações domésticas ou estrangeiras, visando ocupá-la com agricultura, indústria, residência, comércio, extração de recursos e projetos de infraestrutura. Também persiste a força como meio de criação e reprodução do mundo capitalista, para a abertura de oportunidades para o acesso ao mercado, a negócios, investimento e extração de recursos.

De acordo com Hall (2013), duas transformações históricas quebraram a conexão entre território, riqueza e poder do Estado. Uma foi a revolução industrial, em que enormes quantidades de produção industrial em pequenas áreas, Estados e populações ricas tornaram-se dissociadas da extensão de seu território e aumentaram a produtividade como uma alternativa da riqueza e do poder do Estado. A segunda foi a expansão do capitalismo, a qual permitiu a separação total entre a propriedade e o controle sobre a terra. Isso encorajou negócios de aquisição de bens em outros países, e os investimentos estrangeiros permitiram à economia política capitalista obter lucro e extrair recursos do território de outros países que não estavam sob seu controle político.

O autor cita o caso do Brasil, particularmente do Cerrado, como uma das grandes fronteiras de nosso tempo. A região é um dos centros dinâmicos da economia política mundial do século XXI, dado o rápido aumento da demanda por terra pelas corporações locais e estrangeiras. Wolford et al (2013) complementam essa ideia ao afirmarem que a região do Cerrado tornou-se uma reserva territorial para o investimento estrangeiro em agricultura em grande escala. Tal situação impõe novos desafios para as lutas dos movimentos sociais do campo pela reforma agrária. O contexto atual apresenta outra correlação de forças, segundo a própria avaliação do Movimento dos Sem Terra (MST, 2013), com poderes de coerção e de consenso mais fortes do que os dos latifundiários tradicionais e com novos 
atores, como os grandes proprietários rurais, o capital financeiro e as empresas transnacionais. Sendo assim, a reforma agrária se insere na luta contra o modelo do capital, e as disputas se ampliam para o controle das sementes, da agroindústria, da tecnologia, dos bens da natureza, da biodiversidade, das águas e das florestas.

Segundo Oya (2013), a vasta literatura da estrutura e da economia política agrária tem ensinado que existem muitas diferentes camadas de exploração sob o capitalismo na agricultura, como: autoexploração pelas famílias lutando pelos meios de subsistência, frequentemente implicando exploração do trabalho da mulher e de crianças; exploração pelos agricultores capitalistas de larga escala; pelos proprietários não capitalistas; pelos agricultores de pequena ou média escala; via trocas (intermediários versus produtores); por credores, instituições financeiras, fornecedores de maquinários e insumos privados e públicos.

A partir dessa análise, o autor sugere a necessidade de superar as dicotomias presentes nos debates envolvendo pesquisadores e organizações, as quais escondem ou reproduzem vieses conceituais e ideológicos. Cita como exemplo de dicotomias: pequeno versus grande, agricultura familiar versus agricultura capitalista; nacional/doméstico versus estrangeiro; local versus intruso (Estado, capital, migrantes); comida versus ausência de comida e consumo doméstico versus exportação; autoemprego versus assalariamento rural; subsistência versus orientação para o mercado. Oya (2013) entende que um meio de transcender tais dicotomias seria trazer para o centro do debate o trabalho e a exploração, como categorias analíticas e empíricas, bem como ampliar a análise focada apenas na terra, considerando-se o capital como determinante da produção.

Outra dicotomia presente nos debates refere-se à relação entre campo e cidade. Diferentemente de como ocorreu em outros contextos históricos, não é mais possível, na atualidade, demarcar as fronteiras entre espaço urbano e rural. Há um acelerado processo de urbanização em curso, que se estende sobre todo o mundo, ainda que em estágios e de formas distintas.

De acordo com Lefebvre (1971), as mudanças econômicas e as transformações nas técnicas de produção estão unidas a importantes movimentos da população, como o êxodo para as cidades e a partir das cidades, a concentração e a descentralização, as reagrupações populacionais e as novas aglomerações. A oposição cidade/campo, segundo o autor, confunde-se a favor de uma oposição em auge, entre a grande cidade e sua periferia. $\mathrm{O}$ fenômeno urbano se apresenta 
como realidade global que traz implicações para o conjunto da vida social, em termos teóricos e práticos.

O que conduz esse movimento é a procura do capitalista pela expansão e o lucro. Para Harvey (2012), uma das maiores oportunidades expansionistas após a II Guerra Mundial foi a urbanização e, especialmente, a suburbanização. Assim, cada vez mais populações empobrecidas são expelidas para a periferia das cidades. O exemplo da China é emblemático: a percentagem da população que reside em áreas rurais decresceu de $74 \%$ em 1990 para $50 \%$ em 2010. O resultado, segundo Davis (2004), é uma paisagem híbrida, um campo parcialmente urbanizado, uma forma nem rural nem urbana, mas uma mistura dos dois.

Segundo relatório da ONU (2013), metade da população mundial vive atualmente em áreas urbanas, sendo que um terço desta população está em favelas e assentamentos informais. É nos países mais desenvolvidos e na América Latina que se registram os níveis de urbanização mais elevados, respectivamente $74 \%$ e $78 \%$.

As transformações nos meios de expansão do capital e nas formas de produção e reprodução da classe trabalhadora na atualidade, particularmente no que diz respeito à realidade do campo, têm profundas consequências nas relações sociais. Observamos uma crescente mobilidade dos trabalhadores e de suas famílias do campo para a cidade, do centro para a periferia, de uma região para outra e, muitas vezes, para além das fronteiras nacionais. Muitos são conduzidos pelo próprio deslocamento do capital; alguns buscam resistir e organizar-se coletivamente. Não temos qualquer dúvida de que esse processo provoca profundas mudanças na escola e na escolarização das crianças e dos jovens. As escolas rurais, no nosso caso de estudo, veem seu futuro ameaçado. Para não serem fechadas, são levadas a se reorganizar por meio de diversas estratégias: agrupamento de escolas, compartilhamento de programas e recursos, redução de despesas, abertura para programas instrumentais de profissionalização e escolarização em curto prazo, entre outros. Também são disputadas por movimentos e organizações sociais que incluem a escola nas suas bandeiras de luta.

\section{AS ESCOLAS RURAIS / DO CAMPO NO BRASIL}

Com o fim da longa ditadura militar no Brasil (1964 a 1985), observamos a retomada de sindicatos e movimentos sociais. Na cidade, as lutas dos trabalhadores metalúrgicos do $\mathrm{ABC}$ paulista ${ }^{4}$, a criação 
da Central Única dos Trabalhadores e do Partido dos Trabalhadores são exemplares. No campo, diversos movimentos sociais de luta pela terra e pela reforma agrária emergem diante da enorme migração rural iniciada nos anos de 1930, do endividamento e do empobrecimento dos pequenos agricultores, do aumento do número de trabalhadores sem-terra frente a um modelo agrícola centrado na produção monocultora e extensiva, dependente do consumo de agrotóxicos e do uso de maquinários fornecidos por empresas estrangeiras.

Os movimentos dos pequenos agricultores, das mulheres camponesas, dos atingidos por barragens, dos sem-terra e de outros travam uma luta incansável pelas condições de produção da vida no campo. As lutas por terra e outros meios de produção e pela reforma agrária passam a ser associadas com reivindicações por políticas públicas, como estradas, postos de saúde e escolas. É uma tentativa de associar as lutas de âmbito econômico com as sociais e políticas.

Considerando o analfabetismo e o baixo nível de escolarização da população rural, o difícil acesso às escolas, a sua precariedade e a baixa qualidade do ensino, bem como o conteúdo dissociado da realidade, compreendemos a importância da luta por escolas presente na agenda dos movimentos sociais do campo. As escolas rurais no Brasil, historicamente, têm estado em desvantagem, apresentando menores níveis de escolarização e maiores índices de reprovação, abandono e defasagem idade-série. Conforme dados do Departamento Intersindical de Estatística e Estudos Socioeconômicos (DIEESE, 2011), o analfabetismo rural é três vezes maior que o urbano, 9,5\% das escolas do campo não têm luz elétrica, as bibliotecas são reduzidas - presentes em apenas $25 \%$ das escolas -, além da desigual formação profissional entre os educadores do meio rural e do urbano. A média dos anos de escolaridade no campo em 2009 ficou em 4 anos para os homens e em 3,9 para as mulheres.

As escolas rurais, criadas no início do século XX, constituemse mais em estratégias de contenção do fluxo migratório do campo para a cidade do que em espaços formativos. Assim, foi oferecida a uma pequena parcela da população rural uma educação instrumental, reduzida ao atendimento de necessidades educacionais elementares e ao treinamento de mão de obra. Ao lado do caráter discriminador do combate à "praga" do urbanismo, a escola assumia caráter nitidamente preventivo contra a desordem social.

Os programas governamentais para as escolas rurais centramse na lógica economicista, buscando despender poucos recursos para escolas pequenas e com poucos alunos, agrupando as escolas 
por meio da nucleação ou mesmo fechando-as, ou implantando programas de "fortalecimento" das escolas, como formação de professores à distância; tele-ensino; programas de escolarização e instrumentalização profissional de jovens; bem como ensino tecnológico direcionado pela lógica empresarial.

Após décadas de sucessivos programas visando manter as pessoas no campo, o processo migratório não cessa. Os jovens, por exemplo, são movidos pela necessidade de dar continuidade aos estudos, visto que as melhores oportunidades educacionais permanecem nas áreas urbanas. Soma-se a isso o crescente desemprego, que tem assolado especialmente os jovens; 81 milhões estavam desempregados no fim de 2009 entre os 620 milhões de jovens economicamente ativos com idade entre 15 e 24 anos, segundo relatório da OIT (2010). De acordo com Davis (2004, p. 199), pelo menos metade da população que vive em favelas no mundo tem menos de 20 anos.

Milhares de trabalhadores saíram do campo em direção à cidade desde o início do século XX. Trabalhadores rurais migraram para novas fronteiras agrícolas, como as regiões Centro-Oeste e Norte do país, como estratégia de sobrevivência. Trabalhadores do Nordeste do Brasil se deslocaram para o Sudeste e o Sul em épocas de colheitas, muitos dos quais não retornaram. Agricultores viram sua terra ser inundada pela construção de hidrelétricas e foram levados a se mover para outros lugares. Famílias sem-terra ocupam áreas improdutivas e lutam pela conquista de terra em novos lugares. Jovens e também adultos pais de famílias saem do Brasil para trabalhar durante o verão na Itália, na Alemanha, em Portugal, nos Estados Unidos e em outros países. Conforme análise de Hobsbawm (1991), os trabalhadores vagueiam pelo mundo em busca de trabalho. São trabalhadores sem pátria, sem lugar fixo, que têm a mobilidade como elemento central de sobrevivência.

À medida que as áreas rurais perdem sua "capacidade de armazenamento", as

favelas tomam seu lugar, e a "involução" urbana substitui a involução rural como ralo da mão de obra excedente, que só consegue acompanhar a subsistência com façanhas cada vez mais heroicas de autoexploração e uma subdivisão competitiva ainda maior dos nichos de sobrevivência já densamente povoados. (DAVIS, 2004, p. 211)

Na década de 1980, há uma pressão por parte dos movimentos sociais para que a educação rural seja pauta dos temas estratégicos para a redemocratização do país. Passam a atuar juntos sindicatos de trabalhadores rurais, movimentos sociais, organizações comunitárias, educadores ligados à resistência à ditadura militar, partidos políticos 
de esquerda, sindicatos e associações de profissionais da educação, setores da igreja identificados com a Teologia da Libertação e as organizações ligadas à Reforma Agrária.

Nesse contexto, nasce um movimento nacional de educação do campo, tendo como ponto de partida a crítica à educação rural. Ele é organizado pela Articulação Nacional por uma Educação do Campo e por meio de conferências nacionais. Tal movimento pressiona o Estado para promover políticas públicas para o campo e a educação. Como consequência, em 2002, são aprovadas as Diretrizes Operacionais para a Educação Básica nas Escolas do Campo, e em 2004 é criada, no âmbito do Ministério da Educação, a Secretaria de Educação Continuada, Alfabetização e Diversidade, à qual está vinculada a Coordenação-Geral de Educação do Campo ${ }^{5}$.

Os principais programas e políticas para a educação do campo criados na última década são: o Fundo de Manutenção e Desenvolvimento da Educação Básica (Fundeb), que prevê a distribuição de recursos em função do desenvolvimento de cada região e do número de alunos de cada escola; o Pró-Jovem Campo - Saberes da Terra, programa de escolarização e qualificação profissional inicial de jovens agricultores familiares do campo; o Programa Escola Ativa, em continuidade ao Fundo de Fortalecimento da Escola (Fundescola), voltado para as escolas multisseriadas do campo; o Programa de Apoio à Formação Superior em Licenciatura em Educação do Campo (Procampo), com base na formação por áreas de conhecimento; o Programa Nacional de Educação na Reforma Agrária (Pronera), visando à alfabetização e à escolarização de jovens e adultos de áreas de assentamentos rurais.

Desde a instituição desses programas, vimos observando uma disputa teórica e política pela educação do campo. Por parte do Estado, há um enfraquecimento dos programas institucionais para as escolas, o que expressa a política do governo de atender minimamente a algumas demandas dos pequenos agricultores e sem-terra e fazer muitas concessões ao capital e aos negócios relativos à terra e a seus recursos. Desse modo, ganham espaço programas compensatórios, assistencialistas e instrumentalistas. ${ }^{6}$

No que se refere aos estudos sobre a educação do campo, observamos análises que se pautam numa dualidade entre campo e cidade ou entre a educação do campo e a educação que se desenvolve em outros espaços, como o urbano. Há, algumas vezes, uma visão romântica da vida do campo e da educação que lá se desenvolve, pautada 
num modo de vida alternativo, natural, sustentável, livre dos problemas urbanos, como a precarização da vida e do trabalho, a violência, as drogas e outros problemas que afetam especialmente as grandes cidades.

A educação do campo é apresentada por alguns estudiosos como um novo paradigma ${ }^{7}$ que tem como base a agricultura camponesa em oposição ao agronegócio. Há uma revalorização da agricultura familiar e da categoria campesinato.

Martins (1983) reedita as palavras "camponês" e "latifundiário" na delimitação dos problemas sociológicos no Brasil na década de 1970 e se constitui em referência para muitos estudos. O autor defende a tese de que o camponês é excluído sob múltiplas formas: política, econômica, conceitual e ideológica. Compartilhamos da crítica de Villar (1985) à noção de "economia camponesa", a qual nega a categoria "modo de produção" e isola os problemas do campo. $\mathrm{Na}$ realidade, não existe um modo de produção camponês, de onde desapareceriam as distinções e as lutas de classes próprias do capitalismo. Há a coexistência do campo e da cidade; a cidade não pode viver sem o campo e coloca-o a seu serviço por meio de complexas vias.

Numa avaliação com a qual concordamos, Oliveira (2002) trata do desenvolvimento contraditório e desigual do capitalismo brasileiro e de suas manifestações no campo, mostrando a indissociabilidade entre indústria e agricultura, bem como a unidade entre campo e cidade, para além das análises dualistas. Com base nessa compreensão, a educação do campo não pode ser sustentada por antagonismos, pelo contrário, ela é a expressão particular de uma realidade universal.

Quanto aos movimentos sociais, estes continuam a travar lutas essenciais para a sobrevivência num contexto em que a reforma agrária não se efetiva. Há dificuldades de mobilização de sua base quando as reivindicações não são atendidas. Em meio a muitas contradições, seguem construindo formas cooperadas e avançadas de organização do trabalho, da produção e da educação.

Experiências educativas em assentamentos e acampamentos do Movimento dos Sem Terra desafiam a forma e o conteúdo da escola capitalista. Elas se pautam na elaboração coletiva de projetos políticopedagógicos, na formação e no engajamento político dos educadores, na auto-organização dos estudantes e na relação com o trabalho e a vida social. Entretanto, como escolas públicas mantidas pelo Estado, enfrentam inúmeros problemas relativos à estrutura física, ao financiamento, aos recursos humanos, aos materiais pedagógicos e ao direcionamento político-pedagógico. São a expressão da contradição de uma escola mantida pelo Estado e disputada pelos trabalhadores. 


\section{O PROJETO ESCOLAS RURAIS EM PORTUGAL}

Num quadro de regressão e desertificação demográficas, de envelhecimento da população, de perda do dinamismo social, os quais se expressavam em indicadores escolares e educativos de insucesso, abandono, cursos incompletos e analfabetismo, foi criado o Projeto Escolas Rurais. De âmbito nacional, com aproximadamente 20 anos, é ao mesmo tempo fruto e gerador de experiências educativas com escolas rurais.

O contexto português de envelhecimento progressivo da população local, de restritivas pensões de aposentadoria, de deficiente cobertura de saúde e de assistência aos mais velhos penaliza sobremaneira as comunidades rurais. De acordo com Amiguinho (2005), a escola é, muitas vezes, o serviço que resta depois de todos os outros terem desaparecido ou sido suprimidos pelo Estado. "As ameaças à escola, que fragilizam a sua existência ou ditam o seu encerramento, são uma das dimensões do problema mais geral que afeta os meios rurais e daquilo que Educação em meio rural e desenvolvimento local neles se reflete como resultado das políticas públicas" (AMIGUINHO, 2005, p. 9).

O Projeto Escolas Rurais é desenvolvido no âmbito do Instituto das Comunidades Educativas (ICE), o qual reúne diversas experiências educativas inovadoras, tendo como base o vínculo com as comunidades envolvidas e a abertura para uma intervenção de caráter social. O instituto tem a dimensão educativa como central nos projetos que coordena e desenvolve, além da perspectiva de desenvolvimento local e do trabalho com setores excluídos. Há um conjunto de experiências educativas desenvolvidas pelo ICE que podem ser consideradas, de acordo com Canário e Santos (2002), como "portadoras de futuro" no que diz respeito à problemática da contextualização da ação educativa escolar, propondo uma nova relação entre a educação e o local.

O movimento das escolas rurais pode ser conhecido por meio de seus projetos, os quais buscam transformar os obstáculos das escolas rurais em recursos a gerir e em ponto de partida para construir uma escola diferente daquela no modelo existente. Podemos exemplificar por meio da metodologia do "Dia Diferente", a qual permite momentos regulares de encontro entre crianças de diversas escolas, realizados em cada uma das aldeias pertencentes ao projeto, envolvendo as comunidades locais.

Os projetos "Onde está o carteiro" e "Correspondência Escolar" expressam a aproximação entre escolas, professores e comunidade na percepção de um problema comum entre eles e na 
procura de soluções: a aposentadoria do carteiro, com a decisão das autoridades de não o substituir. O projeto "Velhos são os trapos" (primeiro nome do projeto) indica que os sujeitos privilegiados na intervenção são os idosos e as crianças, além de ser instrumento para a necessária relação entre saberes locais e conhecimento universal. No interior desse projeto, diversas iniciativas foram desencadeadas, como a construção de um "Centro de Convívio" na escola de Ouguela; a criação da "Oficina de Marionetas", de Santo Aleixo, que teve a colaboração do arsenal da tradição e da cultura dos idosos; a Casa Museu de Alpalhão, que envolveu não só a busca do patrimônio cultural local, mas também a animação pedagógica.

Outra experiência no âmbito do Projeto das Escolas Rurais refere-se à Quinta de Educação e Ambiente da Lagoa de Santo André, que envolve diversas escolas rurais da região num trabalho conjunto de educação ambiental, desenvolvido numa reserva natural no Alentejo Litoral. A reserva foi assumida como um território educativo em construção, "integrador de conhecimentos advindos dos ensinos formal, informal e da própria vida, conciliando componentes até aqui um pouco desencontrados: o desenvolvimento, a identidade cultural e o conhecimento do ambiente físico e natural com toda a riqueza nele inerente" (D'ESPINEY; PEREIRA, 2002, p. 31).

O pressuposto do Projeto das Escolas Rurais é o de que "a escola muda à medida que muda a sua relação com a comunidade" (AMIGUINHO, 2003, p. 37). Segundo um professor da escola na aldeia de Ouguela, com apenas três alunos em 2005, "quando uma escola fecha, há uma comunidade que morre um pouco mais"8.

Sarmento (2003), com base no relatório que desenvolveu de revisão institucional do Projeto das Escolas Rurais, afirma que este é um movimento social de base educacional que se confronta com uma visão de mundo hegemônica, a qual encara a educação de forma mercantilista. Observa uma "concepção de escola pelo mundo de vida e não como mera instituição de socialização, como espaço intergeracional, e não só como espaço exclusivamente das crianças, e como elo de uma política social, e não apenas como instituição com uma função exclusiva técnico-educacional" (SARMENTO, 2003, p. 69).

Em síntese, os projetos em torno do movimento das escolas rurais incidem não só nas escolas, mas também no meio social, cultural e econômico em que elas estão situadas. A formação de professores e alunos com base na intervenção local; o trabalho coletivo, envolvendo diversos sujeitos sociais e intergeracional; a sensibilização, a problematização e a busca conjunta de soluções para problemas locais; a superação das fronteiras entre o mundo escolar, a vida real e 
o trabalho; o questionamento do modelo escolar; a articulação entre os saberes locais e o conhecimento universal; e a reapresentação na cena política e educacional das esquecidas e marginalizadas pequenas escolas rurais ou escolas isoladas são alguns dos elementos a destacar.

Os professores e os coordenadores que levam adiante o projeto enfrentam muitos problemas - devido ao fato de a escola rural estar em permanente ameaça, bem como o próprio espaço rural, que se transforma rapidamente -, associados com as dificuldades relativas à estrutura das escolas e à grande rotatividade dos professores. Um dos maiores problemas refere-se ao financiamento, o qual é pautado por uma lógica oposta à da intervenção socioeducativa e pode levar à descontinuidade das ações ou mesmo à determinação de projetos de acordo com as linhas de financiamento disponíveis - em Portugal e na Comunidade Europeia.

Canário (2003) assinala as contribuições de um movimento de intervenção na escola rural para a construção de um pensamento sobre o político, o social e o educativo, como ponto de partida para a construção de uma escola completamente diferente, anunciada em experiências que já existem. Alerta, entretanto, para a idealização da escola rural, no sentido de preservá-la como está, e para o mito em torno do espaço local como algo idílico.

\section{O COMPARTILHAMENTO DE PROGRAMAS E RECURSOS NAS ESCOLAS RURAIS DO ESTADO DE NOVA YORK, ESTADOS UNIDOS}

Em 1990, mais de 60\% dos norte-americanos viviam em áreas rurais, definidas como pequenas cidades (com menos de 2.500 habitantes), campos e fazendas. Hoje, mais de $80 \%$ vivem em áreas urbanas; as dez grandes áreas metropolitanas sozinhas contam com mais de $25 \%$ da população do país (LICHTER; BROWN, 2011).

A presença de imigrantes nas áreas rurais, os quais se submetem a longas jornadas de trabalho e baixos salários, é um fator determinante na agricultura do país, bem como na remodelação da ocupação dos espaços rurais e da própria escola, com a presença de seus filhos. Eles têm alterado a paisagem de muitas cidades e também do campo, conforme atesta o subtítulo do livro de Davis (1999), "latinos reinventam as grandes cidades dos Estados Unidos". O autor observa o crescimento da população latina, a qual tem superado a população africana-americana, que se constitui no segundo grupo étnico-racial no país. Tal situação tem um significado geopolítico: latinos dos Estados Unidos já são a quinta maior "nação" da América Latina, depois de Brasil, México, Colômbia e Argentina. 
Davis (1999) observa que os imigrantes latino-americanos formam um círculo vicioso, com baixos salários e baixos níveis de habilidades e educação inadequada. Quase metade dos latinos com idade entre 25 anos ou mais em Nova York não tem um diploma do ensino médio, assim como $58 \%$ dos imigrantes mexicanos adultos em Los Angeles. Longas jornadas de trabalho, juntamente com responsabilidades familiares e um país sem classes de educação de adultos, fazem com que seja muito difícil para a maioria dos adultos latinos melhorar suas habilidades ou terminar o nível secundário. Seus filhos são as principais vítimas da superlotação e da falta de pessoal em sistemas escolares em ruínas nas grandes cidades. A crise do ensino público, combinada com a pobreza das famílias (condição de $40 \%$ de todas as crianças latinas), empurra demasiados adolescentes prematuramente para o mercado de trabalho (DAVIS, 1999, p. 36).

Segundo Lichter e Brown (2011), o rural e as pequenas cidades estão passando por uma nova urbanização. As inovações tecnológicas têm facilitado o rápido - e com relativo custo menor - movimento de informação e capital (por meio, por exemplo, de internet, TV por satélite e cabo, banda larga). Entretanto, corporações multinacionais aumentam o domínio do comércio local e ditam os preços dos produtos e dos serviços. De acordo com Woods (2006), a privatização das indústrias nacionais e utilidades tais como bancos, recursos energéticos e companhias de telecomunicação dramaticamente reduziram o papel do Estado na provisão dos serviços rurais e expuseram esses serviços às demandas das forças do mercado. Como consequência, setores e serviços que são considerados ineficientes, antieconômicos ou com insuficiente lucro têm sido fechados ou restritos; e diferentes preços são introduzidos para alguns serviços, refletindo variações geográficas no atual custo de entrega.

Observa-se, assim, o fechamento de lojas, correios, casas públicas, bares e escolas nas vilas rurais. Esse é contestado por campanhas preocupadas com o impacto na vida da comunidade; uma das mais fortes campanhas de luta envolve o fechamento das escolas rurais.

De acordo com Woods (2006), a racionalização das escolas rurais tem continuado a ser uma característica da política educacional em vários países, incluindo Estados Unidos, Inglaterra, Canadá, Nova Zelândia, Irlanda, Alemanha, Suécia, Finlândia e Hungria (RIBCHESTER; EDWARDS, 1999; ROBINSON, 1990, citados por WOODS, 2006). $\mathrm{Na}$ França, mais de 1.400 comunidades rurais perderam suas escolas entre 1988 e 1994 (INSEE, 1998 citado por WOODS, 2006), enquanto 415 pequenas escolas rurais foram fechadas nos Estados Unidos entre 1986-7 e 1993-4 (NCES, 1997 citado por WOODS, 2006). 
Lichter e Brown (2011, p. 572) indicam que um terço dos graduados em nível universitário migrou da área rural, de onde procederam 20\% dos diplomados no ensino médio. Observam alta taxa de migração entre jovens.

O Departamento Federal de Educação, do Centro Nacional de Estatísticas da Educação, e o Censo dos Estados Unidos (Federal Departmentof Education's National Center for Education Statistics and the U.S. Census Bureau) categorizam todos os distritos escolares do país em um dos quatro grupos: cidades, subúrbios, pequenas cidades e áreas rurais. Cada grupo é, então, subdividido em três categorias adicionais; as escolas rurais são divididas da seguinte forma, de acordo com a distância em relação a uma área urbanizada: marginal, distante e remota. ${ }^{9}$

Segundo informações do Centro para Escolas Rurais (New York State Center for Rural Schools), sediado na Universidade de Cornell, o Estado de Nova York tem 400 distritos escolares rurais, estabelecidos em áreas rurais e em locais distantes ou remotos, com aproximadamente 360 mil estudantes. Dos alunos desses distritos escolares, 7,5\% são considerados minorias, e 28,7\% estão qualificados para almoço gratuito ou a preços reduzidos. Desde os anos 2000, o Estado tem perdido 200 mil cidadãos por ano devido à emigração. As escolas rurais enfrentam um conjunto de desafios visando à sua consolidação, à melhora de programas acadêmicos e extracurriculares, à oferta de préescola universal, além de mudanças nas matrículas e na demografia. ${ }^{10}$

Conforme resultado de pesquisa de Siplle e Killeen (2013), apesar da forte variação na riqueza de propriedade e nas taxas de impostos no norte do Estado de Nova York, a condição financeira das escolas é bastante equitativa. No entanto, dada a relativa homogeneidade das despesas entre os distritos, essa paridade financeira pode não suportar adequadamente as necessidades de ensino das comunidades mais pobres e rurais. Os autores consideram que a disponibilidade insuficiente de recursos contribui para as diferenças entre os tipos de serviços ofertados aos alunos, incluindo a qualidade dos professores.

Siplle (2013) vem desenvolvendo pesquisas sobre os impactos das escolas na vitalidade das comunidades e sobre os serviços compartilhados nas escolas municipais. Observa um duplo movimento: os impactos das escolas nas comunidades e das comunidades nas escolas. Segundo o autor, no período de 1990 a 2010, aumentou o número de vilas sem escola e diminuiu o número de vilas com escolas, especialmente as pequenas vilas. Ele apresenta gráficos com dados do valor médio de casas em vilas com escola e sem escola. Em vários desses locais, a escola não está localizada no 
seu interior, mas a uma distância de $0,75 \mathrm{~km}$ até mais de $7,5 \mathrm{~km}$ do local onde a criança pega o ônibus até a escola.

Dexter, Van Buren e Steele (2013) apresentam a experiência de sete escolas do Distrito Escolar de Washington as quais compartilham programas e recursos. O distrito escolar tem se comprometido com a expansão dos serviços compartilhados, a reorganização das escolas e o potencial para consolidar a fusão dos distritos escolares.

Os autores avaliam que o compartilhamento de professores e técnicos permitiu melhor utilização de suas especialidades, bem como eficiência e economia em curto prazo, por meio da diminuição do número de recursos humanos nos últimos dez anos. Tais estratégias são, de alguma forma, respostas às restrições financeiras, as quais forçam os distritos escolares a reorganizarem a alocação dos recursos. Entretanto, Dexter, Van Buren e Steele (2013) entendem que o modelo colaborativo acima apresentado mantém a identidade das escolas e das comunidades, preserva sua autonomia, maximiza oportunidades acadêmicas e permite custo eficiente.

\section{OS LIMITES DAS SOLUC̣ÕES PROPOSTAS PARA AS ESCOLAS DO CAMPO}

Mesmo reconhecendo as expressivas diferenças nas condições das escolas rurais nos três países (infraestrutura, professores, recursos didáticos, acesso à internet, transporte escolar e outros), bem como as diferenças nas vilas, nas aldeias ou nas comunidades rurais, podemos encontrar muitos elementos em comum ${ }^{11}$. Todas elas enfrentam problemas relativos à diminuição do número de alunos, ao fechamento das escolas, à nucleação ou agregação, à distância percorrida pelos alunos para chegar à escola, bem como as restrições orçamentárias que forçam as escolas a buscarem alternativas para a redução de gastos.

Além disso, todas as escolas estão situadas em áreas com profundas mudanças, sujeitas ao acelerado processo de urbanização e à diminuição de terras para cultivo, as quais vão se tornando disponíveis para a agricultura de larga escala e a monocultora, a indústria, o comércio, a extração de recursos, a construção de rodovias e projetos de geração de energia, a criação de redes hoteleiras e áreas de lazer.

O Estado, como um dos alicerces do capital, assume o papel de tornar a terra disponível para corporações domésticas ou estrangeiras. Desse modo, atua nas áreas rurais por meio de limitadas concessões para a pequena e diversificada produção agrícola e de políticas compensatórias para os pequenos agricultores, os sem-terra, os trabalhadores assalariados permanentes e temporários e os imigrantes. 
Como resultado de tal política, as escolas em meio rural são penalizadas por meio da restrição orçamentária, sendo forçadas a aceitar programas escolares de baixa qualidade, com flexibilização dos conteúdos e foco na gestão racional, apoiados por organismos internacionais e dissociados das condições de acesso e permanência na terra, bem como das lutas por educação rural/do campo - como é o caso do Programa Escola Ativa no Brasil ${ }^{12}$-, ou, ainda, sendo levadas a inventar estratégias para conter despesas, como é o caso do compartilhamento de programas e recursos humanos no Estado de Nova York.

No limite, as escolas são fechadas, e os alunos têm que se deslocar para escolas mais distantes, em condições de transporte inseguro, irregular, inadequado para crianças e com longo trajeto e tempo de espera. No caso dos Estados Unidos, os transportes são melhores, entretanto, os estudantes também percorrem alguns quilômetros para alcançar a escola e gastam tempo na espera e no trajeto do ônibus.

Observamos os limites das soluções propostas para a escola em meio rural nos três contextos estudados. No caso do Brasil, a pressão dos movimentos sociais por políticas públicas para o campo e para as escolas levou o governo a criar algumas ações, entretanto, limitadas por vários aspectos: limite orçamentário; natureza e qualidade falhas dos projetos; os programas que não têm garantia de continuidade, visto não se constituírem em políticas de Estado. Do lado dos acadêmicos, houve um aumento no número de pesquisas e projetos dirigidos para a formação de educadores, alimentando-se o debate nacional sobre a educação do campo, entretanto, muitos deles foram limitados por análises dualistas ou utópicas, vendo a escola como espaço para difusão dos "saberes camponeses", mais do que espaços de socialização do conhecimento historicamente referenciado.

A crítica ao urbanismo tem-se constituído num dos principais argumentos utilizados no combate ao êxodo rural pela educação. A ideia é a de que o campo é perturbado pela mudança indesejada e externa da cidade. Williams (1973, p. 45) observa por meio da literatura que o recurso à ideia de um passado feliz e ordeiro joga contra a desordem e o distúrbio do presente. Como idealização, baseada na situação temporária e no profundo desejo por estabilidade, serve para cobrir e permitir escapar das implacáveis contradições de nosso tempo.

No caso dos Estados Unidos, ainda que muitos projetos busquem revitalizar a escola e o espaço rural, esses são orientados pela lógica da eficiência e da economia de gastos, por meio do chamado "modelo colaborativo" entre as escolas rurais, levando à diminuição do número de recursos humanos e à economia com materiais e infraestrutura. Ainda que não mencionado pelos autores 
aqui estudados, supomos que a diminuição de professores e técnicos implica a sobrecarga dos que permanecem no quadro, os quais passam a atuar em mais de uma escola, tendo que atender a um conjunto maior de estudantes e necessitando se deslocar de uma vila para outra.

Com relação ao movimento das escolas rurais em Portugal, ainda que fruto da articulação de organizações, educadores e comunidade, ele está limitado a ações de desenvolvimento local e a projetos que respondem aos problemas imediatos e concretos. Ainda que se possam desencadear mudanças nos envolvidos e questionar o modelo escolar, apresenta dificuldades de se constituir em potencial emancipador.

Portugal é um país onde os movimentos sociais têm uma expressão social limitada, esporádica e difusa na avaliação de Sarmento (2003). Nesse contexto, não podemos sobrevalorizar as experiências educacionais e sociais em termos de capacidade de mudanças de maior envergadura. É uma situação bastante diferenciada em relação a uma proposta educativa desenvolvida no interior de um projeto político, como é o caso, por exemplo, do Movimento dos Sem Terra, no Brasil, o qual busca instaurar uma forma nova de organização do trabalho e da vida, com base na cooperação. Sabemos que a ruptura com o modo de controle sociometabólico do capital (MÉSZÁROS, 2002) é global e universal, para além das soluções locais, parciais e gradativas.

Diversos programas, projetos e políticas para a escola rural têm se apresentado como novidade, entretanto muitos deles insistem na possibilidade de superação das desigualdades sociais por meio de políticas educacionais. Políticas estas que, mesmo buscando a equalização, continuam a reservar à classe trabalhadora uma escola e programas educativos diferenciados, os quais flexibilizam e limitam o acesso aos conhecimentos mais avançados concernentes ao desenvolvimento da humanidade.

Além disso, tais programas não têm conseguido conter o fechamento das escolas, nos três países estudados e em muitos outros, e não são capazes de manter os jovens no campo, os quais emigram com a expectativa de encontrar melhores e mais avançados níveis escolares e, especialmente, à procura de trabalho nas cidades.

O futuro das escolas está diretamente relacionado com o futuro do campo, um espaço, como já anunciado aqui, em crescente urbanização e mudanças, que implicam a saída de grande parte da população rural, visto que o modelo agrícola capitalista predominante é o do agronegócio e da financeirização da agricultura, mantendo poucos trabalhadores no campo. Estes se tornam mais sazonais, migrando para diferentes regiões de acordo com os períodos de colheita. 
De acordo com Breman (2009, p. 33), o retorno para o campo tem sido alardeado pela mídia ocidental como uma opção nestes tempos difíceis de crise. A suposição é a de que grande número de migrantes rurais despedidos nas cidades pode retornar para as fazendas de suas famílias e ser absorvido no trabalho agrícola. Os consultores do Banco Mundial afirmam que a agricultura poderia agir como um reservatório de captação de força de trabalho em outros setores. $\mathrm{O}$ autor derruba tal mito ao evidenciar, por meio de sua pesquisa, que os migrantes não voltaram às suas vilas, porque faltava terra ou outras formas de capital. Não havia fazendas de família para onde voltar; a partida dos sem-terra ou pobres da terra foi parte da estratégia de enfrentamento. Esse proletariado rural tem se tornado redundante, $\mathrm{e}$ não tem demanda por sua força de trabalho em seu lugar de origem.

Tal problemática está relacionada ao fato de que os agricultores mais capitalizados, usando modernas tecnologias, sementes e insumos, produzem mais comida por hectare de terra e horas de trabalho, tornando possível alimentar o mundo com menos pessoas trabalhando como agricultores. Como consequência, observam-se a urbanização e a crescente saída do campo, afastando pessoas da atividade agrícola. Segundo Hall (2013), a América do Norte, o Leste Europeu e parte do nordeste da Ásia têm o mais alto nível de urbanização e somente de $2 \%$ a $3 \%$ da população engajada na agricultura.

Portanto, este é o real obstáculo para a vida e o trabalho no campo, bem como para as escolas: um estágio das forças produtivas que tem reduzido a necessidade de trabalho vivo. No caso de uma sociedade plenamente humana, que não estivesse centrada na exploração e na produção de mais-valia, teríamos alcançado um estágio avançado de libertação do trabalho abstrato, podendo nos dedicar a muitas atividades enriquecedoras do espírito humano. Entretanto, neste tempo histórico, os que não detêm os meios de produção dependem da venda da força de trabalho para a sobrevivência.

$\mathrm{Na}$ ausência de trabalho para todos, resta a barbárie, ou a capacidade coletiva de criar uma nova ordem social, com a apropriação do espaço (rural e urbano) de modo equilibrado e sustentável, no sentido radical do termo, bem como formas educativas/escolares que tenham como foco a formação humana, que possibilitem o desenvolvimento total, completo, em todos os sentidos, das potencialidades humanas: intelectuais, artísticas, estéticas, produtivas, corporais. Nessa direção, não nos resta dúvida de que qualquer mudança significativa implicaria mudança revolucionária. 


\section{REFERÊNCIAS}

AMIGUINHO, Abilio. Educação e mundo rural: percursos biográficos, intervenção e pesquisa. Educação, Sociedades \& Culturas, Porto, n. 20, 2003. p. 9-42.

. Educação em meio rural e desenvolvimento local. Revista Portuguesa de Educação, Braga, n.18, v.2, 2005. p. 7-43.

BREMAN, Jan. Myth of the global safety net. New Left Review, London, n. 59, sept./oct., 2009. p. 29-36.

BERNSTEIN, Henry. Food sovereignty: a skeptical view. In: FOOD SOVEREIGNTY: A CRITICAL DIALOGUE. INTERNATIONAL CONFERENCE, 2013, New Haven. Anais... Yale University, 2013.

CANÁRIO, Rui. Escola rural: pensar o educativo, o social e o político. Aprender, Revista da Escola Superior de Portalegre, Portalegre, n. 28, 2003. p. 96-102.

CANÁRIO, Rui; SANTOS, Irene. (Orgs.). Educação, inovação e local. Setúbal: Instituto das Comunidades Educativas. Cadernos ICE, 6, 2002.

DAVIS, Mike. Magical urbanism: latinos reinvent the US big city. New LeftReview, London, n. I/234, march/april 1999. p. 3-43.

Planet of Slums. New Left Review. London, n. 26, march/april, 2004. p. 5-34.

D'ESPINEY, Rui; PEREIRA, Isabel. Uma aposta nas novas ruralidades: Quinta de educação e ambiente da Lagoa de Santo André. In: CANÁRIO, Rui; SANTOS, Irene (Orgs.). Educação, inovação e local. Setúbal: Instituto das Comunidades Educativas. Cadernos ICE, 6, 2002. p. 27-37.

DEXTER, James; VAN BUREN, Maureen; STEELE, Jerome. Building a 21 at century regional learning and planning community: a collaborative model. In: RURAL SCHOOL ASSOCIATION CONFERENCE, 2013. Anais... Cooperstown, NY, 2013.

DEPARTAMENTO INTERSINDICAL DE ESTATÍSTICA E ESTUDOS SOCIOECONÔMICOS - DIEESE. Estatísticas do meio rural 2010-2011. 4. ed. Brasília, MDA, 2011.

FERNANDES, B. M.; MOLINA, M. C. O campo da Educação do Campo. In: MOLINA, M. C.; JESUS, S. M. S. A. (Orgs.) Contribuições para a construção de um projeto de Educação do Campo. Coleção por uma Educação do Campo, n. 5. Brasília: Articulação Nacional Por uma Educação do Campo, 2004. p. 53-90.

HALL, Derek. Land. Cambridge/UK, Malden/USA: Polity Press, 2013.

HARVEY, David. Rebel cities: from the right to the city to the urban revolution. London; New York: Verso, 2012.

HOBSBAWM, Eric. A era das revolucões. Rio de Janeiro: Editora Paz e Terra, 1991.

JESUS, S. M. A. Questões paradigmáticas da construção de um projeto político da Educação do Campo. In: MOLINA, M. C.; JESUS, S. M. S. A. (Orgs.) Contribuições para a construção de um projeto de Educação do Campo. Coleção por uma Educação do Campo, n. 5. Brasília: Articulação Nacional Por uma Educação do Campo, 2004. p. 109-130.

LEFEBVRE, Henri. De lo rural a lo urbano. Barcelona: Ediciones Península, 1971.

LICHTER, Daniel T; BROWN, David L. Rural America in an urban society: changing spatial and social boundaries. Annual Review of Sociology, Palo Alto, CA, n. 37, 2011. p. 565-592.

MARTINS, José de Souza. Os camponeses e a política no Brasil. 2. ed. Petrópolis: Vozes, 1983. 
MÉSZÁROS, István. Para além do capital. São Paulo: Boitempo, 2002.

MOVIMENTO DOS TRABALHADORES RURAIS SEM TERRA - MST. Programa agrário do MST. Lutar! Construir a reforma agrária popular! Texto para o $6^{\circ}$ Congresso Nacional, 2013.

OLIVEIRA, Ariovaldo Umbelino. O campo brasileiro no final dos anos 80. In: STÉDILE, J. P. (Org.). A questão agraria hoje. 3. ed. Porto Alegre: Ed. UFRGS, 2002.

ORGANIZAÇÃO INTERNACIONAL DO TRABALHO. Tendências Mundiais de Emprego para a Juventude, 2010. Disponível em: <http://www.oitbrasil.org.br>. Acesso em: 5 de setembro de 2013.

OYA, Carlos. Methodological reflections on 'land grab' databases and the 'land grab' literature 'rush'. The Journal of Peasant Studies, The Hague, n. 40, v. 3, jun. 2013. p. 503-520.

RIBEIRO, Marlene. Educação do campo e escola ativa: contradições na política educacional no Brasil. Educação em Revista, Belo Horizonte, v. 12, n. 2, p. 23-40, 2011.

RUMMERT, S. M.; ALGEBAILE, E.; VENTURA, J. Educação e formação humana no cenário de integração subalterna no capital-imperialismo. In: SILVA, M. M.; EVANGELISTA, O.; QUARTIERO, E. M. (Orgs.). Jovens, Trabalho e Educação: a conexão subordinada de formação para o capital. Campinas: Mercado das Letras, 2012, p. 15-70.

SARMENTO, Manoel J. Educação em meio rural: lógicas de acção e administração simbólica da infância. Aprender, Revista da Escola Superior de Portalegre, Portalegre, n. 28, 2003. p. 62-73. SIPLLE, John W. New research and practice linking school and community vitality: from shared services to school closure. In: RURAL SCHOOL ASSOCIATION CONFERENCE, 2013. Anais... Cooperstown, NY, 2013.

SIPLLE, John W.; KILLEEN, K. Upstate school reform: the challenge of regional geography. Disponível em: <www.nyruralschools.org>. Acesso em: 5 de junho de 2013.

UNITED NATIONS. Habitat Global Activities Report, 2013. Disponível em: < http://www. unhabitat.org/pmss/listItemDetails.aspx?publicationID=3454>. Acesso em: 5 de junho de 2013 .

VENDRAMINI, C. R. A educação e a produção da vida no campo e na cidade: espaços de esperança? Florianópolis: Universidade Federal de Santa Catarina, 2014. 59 p. Relatório.

Território, trabalho e educacão: a simbiose entre campo e cidade na universalização do trabalho coletivo. Ithaca: Cornell University, 2013. 56 p. Relatório Estágio Sênior.

Os processos formativos no contexto do MST: a relação entre trabalho e educação. Florianópolis: Universidade Federal de Santa Catarina, 2010. 120 p. Relatório.

Movimento Educativo Emancipatório: uma revisão das pesquisas sobre o Movimento dos Sem Terra no campo educacional. Florianópolis: Universidade Federal de Santa Catarina, 2008. 242 p. Relatório.

Experiências educativas em associações e cooperativas de trabalhadores: um estudo comparativo entre Brasil e Portugal. Lisboa: Universidade de Lisboa, 2005. 163 p. Relatório Pós-Doutorado.

WILLIAMS, Raymond. The country and the city. Oxford University Press, 1973.

WOLFORD, Wendy et al. Governing global land deals: the role of the state in the rush for land. Development and change, The Hague, n. 44, v. 22, 2013. p. 189-210.

WOODS, Michael. Redefining the 'Rural Question': The New 'Politics of the Rural' and Social Policy. Social Policy and Administration, Mauden, n. 40, v. 6, 2006. p. 579-595. 


\section{NOTAS}

${ }^{1}$ Cf. VENDRAMINI, 2014, 2010, 2008.

${ }^{2}$ Cf. VENDRAMINI, 2013.

${ }^{3}$ Cf. VENDRAMINI, 2005.

${ }^{4}$ Região industrial e metropolitana de São Paulo, constituída pelos municípios de Santo André, São Bernardo do Campo e São Caetano do Sul.

${ }^{5}$ Essa coordenação não existe mais. O que vigora atualmente é a Diretoria de Políticas de Educação do Campo, Indígena e para as Relações Étnico-Raciais, vinculada à Secretaria de Educação Continuada, Alfabetização, Diversidade e Inclusão (SECADI).

${ }^{6}$ São programas destinados a jovens com defasagem idade-série ou que estão fora da escola, visando à escolarização em curto tempo e à preparação inicial para a ocupação no trabalho. Podemos citar: Pro-Jovem Campo, Pronacampo, Pro-jovem, Proeja, Pronatec e outros. Uma crítica aos programas para jovens pode ser encontrada em Rummert, Algebaile e Ventura (2012). ${ }^{7}$ Cf. FERNANDES; MOLINA, 2004; JESUS, 2004.

${ }^{8}$ Informação do diário de campo da pesquisadora.

${ }^{9}$ Informações disponíveis em: <www.nyruralschools.org>. Acesso em: 23 de setembro de 2013.

${ }^{10}$ Informações disponíveis em: <www.nyruralschools.org>. Acesso em: 23 de setembro de 2013.

${ }^{11}$ De acordo com Williams (1973), os detalhes locais dos lugares são diferentes, como é natural entre pessoas diferentes, mas muitas das nossas experiências históricas são essencialmente similares.

${ }^{12}$ Para uma crítica ao programa, cf. RIBEIRO, 2011.

Recebido: 05/11/2013

Aprovado: 11/05/2015

Contato:

Rodovia João Paulo, 1030. Bloco C, Ap. 101

Bairro João Paulo

Florianópolis $|\mathrm{SC}|$ Brasil

CEP 88.030-300 
